\title{
Opinion
}

\section{Why We Should Talk About the Government Tax Tracking Our Daily Moves}

Caroline Calomme*

\section{Introduction}

The number of vehicles on the road continues to increase worldwide despite policies promoting public transport, increasing parking fees and supporting remote work arrangements. As a result, many countries face longer traffic delays, rising maintenance costs, a decline in air quality and a higher risk of accidents. This is why many public authorities in Europe already charge a fee to heavy commercial vehicles to cover the costs of their impact on the infrastructure and the environment. The very same policy can lead to a form of mass surveillance targeting civilians and we should be worried that this issue is largely missing from privacy debates.

Charging a fee for the use of public or private road infrastructure, known as tolling, has existed since Roman times. However, the technologies available to calculate the price to be paid have evolved significantly and electronic tolling collection in the European Union began in the early 1990s. One of those emerging technologies actually makes it possible to track the location of driving vehicles from the start until the end of their journey at a low cost. This is particularly worth paying attention to because in some countries the same fee is also imposed on passenger vehicles. If implemented poorly, a straightforward road tax could enable those who govern to monitor the movements of their citizens on a large scale.

So why are we - legal and ethical experts - not talking about a government tax that could track our daily moves?

The following piece will outline why we need to join the debate and collaborate with technical experts to help manage the risks of tolling schemes by translating general frameworks into practical solutions together.

\section{How Close Are We to Mass Surveillance?}

It is only a matter of time before governments begin to consider using cheaper but more intrusive tolling technology for private vehicles. Let us find out why and how this could happen.

\section{Do We Need to Share Our Location to Use Public Infrastructure?}

Processing personal data, such as location data, as part of a tolling scheme, such as location data, could be justified on the grounds that it is necessary to perform a task in the public interest. But let's question this very assumption: if the task is indeed to collect taxes to fund projects in the public interest while limiting the tax scheme to road users, aren't they already other vehicle taxation measures in place? In fact, vehicles in Europe are also subject to an annual ownership tax, registration fees, fuel tax and VAT on related services and goods. Nevertheless, this might not be enough. Arguably, this does not remove the need for road charging because drivers from other countries are not necessarily contributing through those schemes. In other words, heavy goods vehicles would be able to make use of the roads without paying their share of the costs.

Yet, location is not always essential for a road charge. Policymakers can choose to levy a fee for a given period of time (time-based pricing) or according to the distance travelled (distance-based pricing). There are economic considerations behind this deci-

DOI: 10.21552/delphi/2019/3/9

* Legal Innovation Advocate and Legal Strategist at Lexigogo. For correspondence: <caroline.calomme@protonmail.com> 
sion but this choice also has repercussions on how much information needs to be collected. In the case of time-based pricing, vehicles can drive on a road for a specific period of time, regardless of the frequency or the distance. This means that their location within the road network where the fee is applicable is irrelevant for the pricing model.

In the case of distance-based tolling on the other hand, the price is based on the number of kilometres driven and it is usually billed at the end of each month. Calculating the price as accurately as possible requires identifying the location of the vehicles, at the very minimum at the entry and exit of tolled roads. An argument could be made that distancebased pricing is the only way to distribute the costs fairly by dividing contributions proportionality to the use of each vehicle. It is also worth noting that the European Union has already tried to phase out time-based pricing although this was unsuccessful due to political resistance.

\section{Which Technology Could Make Mass Surveillance Possible?}

In earlier decades, entry and exit gates were installed on specific parts of the road. You received a ticket upon entry and you had to pay the price for the distance that you drove. Although it slows down traffic, installing gates is a practical option for distance-based tolling when only a few stretches of road are taxed. Yet, the size of the network where tolls apply can vary and, in theory at least, it could cover the entire road network. For example, policymakers can decide to levy a fee on all highways and make all use of secondary road free.

While a larger toll network could bring more revenues, it is unrealistic to install toll gates at every possible entry and exit point. Besides, drivers will try to circumvent them by driving on toll-free roads, motivating policymakers to extend the tolling network even more to avoid traffic in residential areas. This

1 DSCR is historically the most widespread system in the European Union

2 EU tolling legislation for heavy goods vehicles already requires OBUs (on-board units) to be compatible with Galileo by 2021. 'Made in the $\mathrm{EU}^{\prime}$ technology might have an influence on policies

3 Each road section is associated with a price, eg 0 for a road where no toll is applicable is why there has been a switch towards installing equipment on the side of the road which can detect the passage of a specific vehicle at a fixed point. This can for example be done thanks to automatic number plate recognition (ANPR), dedicated short-range communication technology (DSRC) or radio frequency identification (RFID). ${ }^{1}$ While it does not require drivers to stop, it might be quite costly to install roadside equipment on a large network and the equipment itself also requires maintenance.

This brings us to the alternative technology option gaining popularity across Europe: Global Navigation Satellite Systems (GNSS). Most applications, including those on your smartphone, currently rely on the American Global Positioning System (GPS) but in 2016 the European Union also launched its own satellite system called Galileo. ${ }^{2}$ Satellite technology has been chosen for heavy goods vehicles in Belgium, Germany, Hungary, Slovakia and soon Bulgaria. Using an on-board unit (OBU), the trip of the vehicle is tracked in real-time to determine the price of the kilometres driven. This means that the position is monitored continuously, whether or not the vehicle is driving on a tolled road. ${ }^{3}$ The price calculation can take place in a back office or on the device. Doing so on the device clearly better protects the privacy of the drivers but it can be difficult to update the pricing scheme or the toll network on the device itself.

\section{Are Tolling Data Used for Other Purposes?}

Beyond generating revenues, tolling is a useful tool to nudge the drivers' behaviour through financial incentives instead of fines in order to implement transport and environmental policies. For example, newer vehicles that pollute less can benefit from a lower fee. It only requires vehicle information but sometimes location data can be essential to influence behaviour. In fact, the scheme can be designed with a variable price depending on where the road users are driving (eg the city centre), in which direction they are driving (eg towards the city) in combination with when they are driving (eg during peak hours). If implemented correctly, nudging can help to reduce traffic congestion, improve traffic safety and lower the frequency of maintenance.

Whether drivers are influenced or not by the costs, governments are authorised to use aggregated tolling 
information such as traffic flow information to shape their future transport policies. It can help to optimise the maintenance and safety of the infrastructure as well as to plan the construction of new roads. It can also assist in identifying the areas where promoting or reinforcing alternative modes of transport is most beneficial. In addition, it can be valuable information when adapting the pricing scheme. With GNSS tolling, it is actually possible to identify the alternative roads chosen by the drivers to avoid toll roads. It is however questionable whether access to this information should be given to the authorities.

In the future, road authorities could re-use passenger tolling information to provide personalised advice to road users. Whereas GNSS is predicted to replace DSRC technology, there are many proponents of smartphone tolling since most drivers already have a smartphone and might not be willing to pay for an OBU. However, this solution is problematic, especially in terms of potential fraud because a smartphone is easier to manipulate and turn off. If those issues are resolved someday, it would be possible to know on which roads a vehicle usually drives most often based on previous tolling data and inform the driver via text messages or notifications about planned road closures or maintenance on this route. It would be a bit complex from a technical perspective but it is still worth keeping in mind as a possible development.

Pricing mistakes can also happen and it is the consumers' rights to issue a complaint and be reimbursed. ${ }^{4}$ Yet, from a data protection perspective, the location data can only be kept as long as necessary. They are initially collected to calculate the fee and bill the individuals so they need to be anonymised or deleted once this purpose is fulfilled. However, identifying a specific trip linked to an identifiable individual is necessary in case of a complaint and is no longer possible if the data are anonymised. In this case, protecting the privacy might actually jeopardise their consumer rights and vice versa. Even if the consumers could be identified only via a vehicle ID number, bank details would still reveal personal information - and ideally the ID number should also change between journeys.

Last but not least, without appropriate legal and technical safeguards, location information could also be used to target ethnical or religious minorities, reveal that a political figure is frequently visiting medical experts, pressure opponents who are found to spend their nights elsewhere, etc. ${ }^{5}$ While these sce- narios might not appear realistic to those who trust their government, a data breach can lead to similar results. Moreover, this information could be relied upon in criminal proceedings, potentially without a warrant. $^{6}$

\section{Do Drivers Still Have a Choice?}

Distance-based tolling for private vehicles already exists in the European Union such as in France or in Portugal. However, in most cases, it is still possible for citizens to choose a manual payment method or to avoid tolled roads. Developments to worry about would be an extension of the toll network, leaving few 'free' roads to drive on, and the obligation to install an OBU in each vehicle to allow continuous location tracking without any mitigating measures. ${ }^{7}$ The freedom of citizens could also be impaired where regular roads are poorly maintained and frequently blocked by traffic jams forcing drivers to choose between convenience and privacy.

The insurance sector has also introduced a 'payas-you-drive' model for consumers. Instead of a standard fee, you only pay according to how much you drive since the risk of having an accident could be lower if you drive less often. However, to achieve the same surveillance effect, all insurance companies would need to offer this product and make it mandatory. Drivers still have the choice not to be tracked when they drive by opting for another plan or by choosing another insurance provider. In fact, this business model does not seem to have gained a lot of traction.

To be sure, tolling does not need to be limited to motor vehicles hence the rise of alternative modes of transport does not guarantee the absence of monitoring. Historically, the levy pertained to the infrastructure and pedestrians or travellers on horseback were also charged to cross a bridge. In a society where the

4 An error could occur if a pricing update is not reflected in the costs, if an incorrect location places a vehicle on a tolled road instead of a 'free' road, if the hardware is defective, etc

5 The absence of data can also be problematic. Corruption might result in specific vehicles being automatically 'undetectable' and not being charged for their travels

6 It should also maybe be the driver's right to obtain proof of his or her location when it could constitute exculpatory evidence

7 In theory, installing many ANPR or DSRC points would reach a similar result but it would be much more costly and would only be allowed on toll roads 
roads would primarily be used by bicycles, a similar scheme could for instance apply to bicycles. Nevertheless, the main issue remains the risk of identification between the vehicle and the driver/payer. This might become less likely if car sharing becomes the norm: the government would tax the car sharing company, which would decide on how to transfer those costs to their customers. Depending on how it is implemented, it could make re-identification at least more difficult. ${ }^{8}$

\section{Conclusion}

Tolling policies are part of a complex ecosystem with public-private partnerships, European and national

8 The implementation of a pay-as-you-drive scheme could nonetheless result in constant tracking by a private party even if the information is not shared with the government legislation and intricate stakeholder relationships between policymakers, transport ministries, road infrastructure operators and authorities, hardware providers and suppliers, telecommunication companies, companies calculating the pricing, companies issuing the bills, companies enforcing the tax and drivers. There are many layers to dig through for what seems to be a quite simple and uninteresting transport policy but there is also a lot to lose by not exchanging and assembling knowledge from different fields.

If we do not pay close attention, we might one day live in a society where the government is de facto equipped with a tool of mass surveillance without even planning on it. It is time for a more diverse range of experts to join the debate and get involved in designing a tolling system for private vehicles that can optimally achieve the desired financial and environmental goals while protecting the rights of citizens. 